\title{
HANDBUCH \\ DER ALTORIENTALISCHEN GEISTESKULTUR
}


Copyright 1929 by Walter de Gruyter \& Co., Berlin W 10 



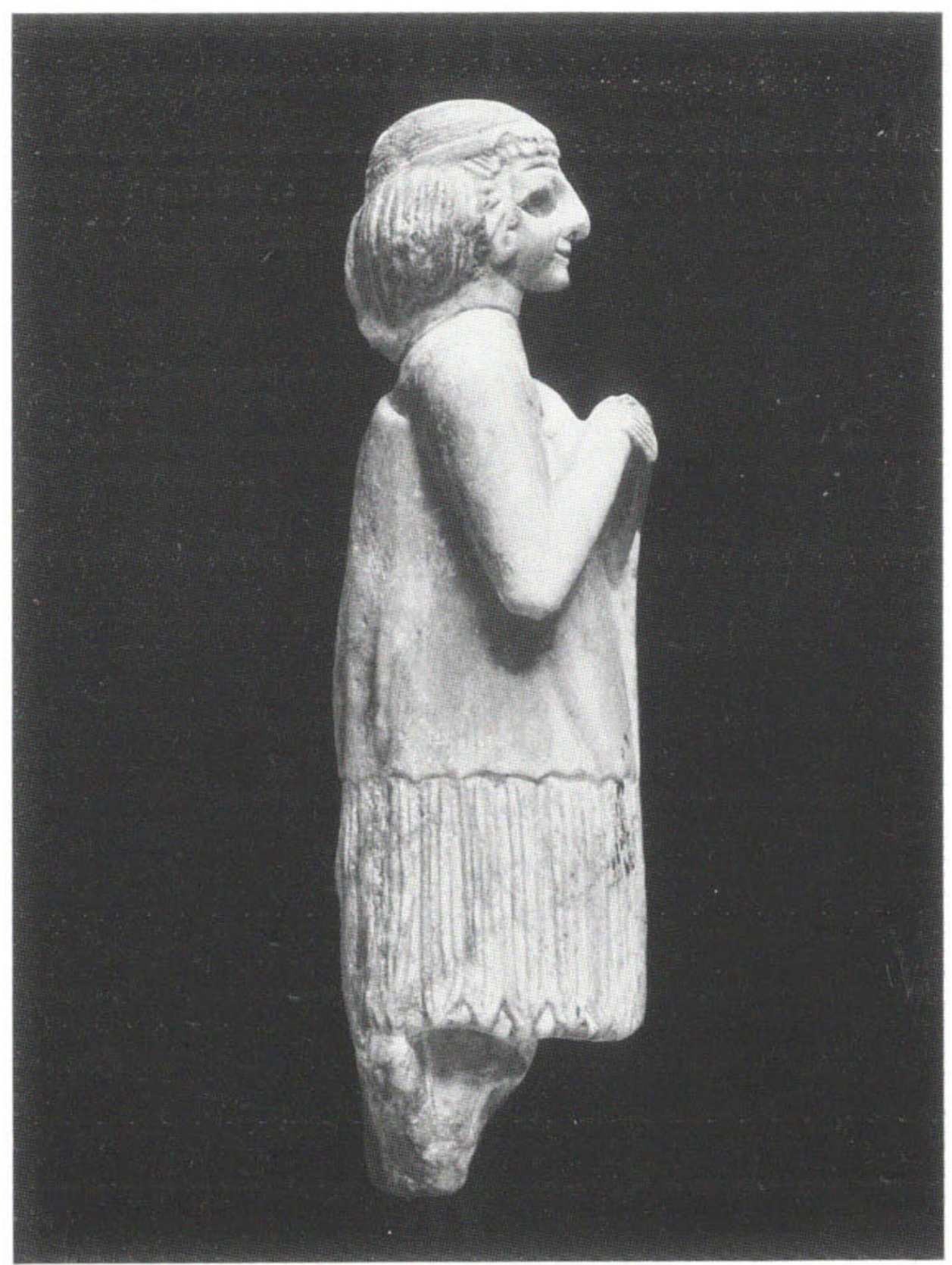

Abb. 1. Statuette einer sumerischen Kïnigin 


\title{
HANDBUCH \\ DER ALTORIENTALISCHEN GEISTESKULTUR
}

\author{
VON
}

D. DR. ALFRED JEREMIAS

A. O. PROFESSOR FOR RELIGIONSGESCHICHTE IN LEIPZIG

ZWEITE, VÖLlig ERNEUERTE AUFLAGE

MIT 260 BILDERN NACH DEN MONUMENTEN

UND 1 STERNKARTE

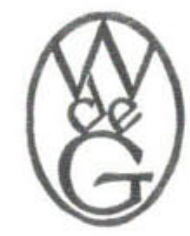

BERLIN UND LEIPZIG 1929

VERLAG VON WALTER DE GRUYTER \& CO. VORMALS G.J. GOSCHEN'SCHE VERLAGSHANDLUNG - J. GUTTENTAG, VERLAGS. BUCHHANDLUNG - GEORG REIMER - KARL J. TROBNER - VEIT \& COMP. 
"So wie droben, ist es auch auf der Erde; denn das Abbild dessen, was in dem Firmament ist, ist hier auf Erden."

"Aller Wunder sei geschwiegen, Die Erde hat den Himmel überstiegen.

Himmel ist unten, Erde ist oben, Dies Minnewunder soll man loben als aller Wunder Wunderproben.* Germanischer Sang

». . Vom Himmel kommt es,

Zum Himmel steigt es,

Und wieder nieder

Zur Erde mub es

Ewig wechselnd $l_{\text {« }}$ 


\section{SEINER MAJESTÄT KAISER WILHELM II. DEM SCHUTZHERRN DER AUSGRABUNGEN VON BABYLON UND ASSUR EHRFURCHTSVOLL ZUGEEIGNET}


